\title{
Towards the science of managing for innovation: conclusion \& future research directions
}

\author{
Anne-Laure Mention \\ anne-laure.mention@rmit.edu.au | RMIT University, Australia \\ João José Pinto Ferreira \\ jjpf@fe.up.pt | INESC Technology and Science, Faculty of Engineering, University of Porto, Portugal \\ Marko Torkkeli \\ marko.torkkeli@lut.fi | Lappeenranta University of Technology, Finland
}

We initiated this series with a view to catalyse and extend the focus on conceptualisation and application of behavioural science methods for managing innovation, albeit from a whole human perspective. We started with the notion that how to increase individual (human) creativity, collaboration productivity and innovativeness in innovation projects is a common concern for most firms. After discussions on the brain-mind-behaviour triad in the beginning, the interim editorial highlighted behavioural experiments as one plausible method to further the science of managing for innovation. In this final piece on the series, we conclude with a caveat on using experimental methods in examining the human side of innovation (Salampasis and Mention 2017) and discuss avenues for future research in innovation management, which increasingly reflects a collaborative affair (Bogers et al., 2017; Heil and Bornemann 2018).

In the previous editorial, we emphasised the role of behavioural experiments in innovation research, motivated by (and designed to address) questions on human behaviour and performance. Innovation research and practice is naturally based on experimentation, be influenced by reflection of past experiences, judgements in current social context or desired future. The primary object of behavioural experiments is to observe the effects on behaviour and performance of participants in purposively developed behavioural task whilst being subjected to (or controlled from) a treatment condition. They are distinct from neo-classical (game-theoretic) economic experiments in that they explain the behaviour in a treatment condition, as compared to relying on economic assumptions of expected utility principle. The underlying assumption being that humans are intentional, goal-oriented and actively seek meaning, self-worth and creativity. They are also consciously aware (and aware of being aware) that their actions have future consequences (known and unknown). Besides, the humanistic perspective suggests that future lies in the 'eye of the beholder'. That is the individual's socio-cognitive ability to imagine future consequences of actions is what ultimately shapes the formulation of new possibilities for $\mathrm{R} \& \mathrm{D}$ management 
(Botha 2016). A key feature of behavioural experiments is that they can accommodate complex variables and contexts and thus allow for integrated abstraction of individual's socio-cognitive capabilities to inform wider innovation procedures in practice. Thus, to examine the effects of underlying psychological variables on behaviour and performance in an otherwise complex social phenomenon of increasingly open and collaborative innovation (Brunswicker \& Chesbrough 2018), it is deemed appropriate to rely on experimental psychology techniques. However, this means that the very setting aimed at deeper understanding of cause and effects, may be contaminated by confounding variables as participants may be asked to receive information, communicate and act in unusual ways, possibly reflecting role-playing or theatrical interactions (see Stokoe, 2014). Indeed, quantitative researchers are under heated debate on the efficacy of the published results from experiments, many of which have failed the replicability tests (Pashler \& Harris, 2012; Pashler \& Wagenmakers, 2012). The concern is so strong that it prompted Nobel laureate Daniel Kahneman to write a letter to the journal Nature as he saw a "train wreck looming" and urging researchers to "collectively do something about this mess"1. A plausible explanation for the failed reproducibility of experimental findings may rest in the theoretical and contextual gaps needing explanations far-fetched from theoretical assumptions (Harding, 2012). The stretching of the truth when coupled with the null hypothesis significance testing (NHST) preference at $5 \%$ threshold for rejecting null hypothesis, provides the perfect breeding ground for folk theories (Johnson, 2013; Wagenmakers, 2007; Wagenmakers et al., 2011). Perhaps, a behavioural experiment aimed at understanding the socio-cognitive capabilities and behaviour of individuals is not complete without some study of the interactions during the innovation process.

It is our view that in advancing the science of managing for innovation, experimental researchers need to consider complementing experimental findings with another commonly implemented technique in studying human behaviour and social interactions - conversation analysis (CA). The value of CA rests in reliance on naturalistic data, and can unveil the convergent and divergent explanations of causal inferences of an otherwise complex phenomenon. Integrating CA in behavioural experiments can allow for limiting the explanations based on mock behaviour (Kuhlen and Brennan 2013). It could enrich the experimental findings by providing an avenue to 'stay conceptually closer to our actual social behavior "in the wild"' (Ruiter \& Albert, 2017, p.97). Further, the rationale for incorporating CA in the experimental settings is based on the studies by Healey et al. (Healey, Howes, \& Purver, 2010; Healey, Purver, \& Howes, 2014) which refuted the highly cited laboratory findings of Branigan, Pickering and Cleland (2000), that people copy the verbal statements or words spoken by another during a dialogue more often than by chance. Indeed, it may not be prudent to believe that experimental findings would reveal effects same as those found in natural settings (Doob and Gross 1968, Shaughnessy, Zechmeister \& Zechmeister, 2015).

Throughout the series, we have focused at the intersection of behavioural science and human aspects of innovation management. We conclude that the approach of integrating interdisciplinary perspectives to study behaviour and performance in innovation management research reflects similar initiatives in neighbouring fields. For instance, behavioural strategy scholars have started to incorporate theoretical and methodological developments in social and cognitive psychology to

1 Kahneman's letter can be found at: https://www.nature.com/polopoly_fs/7.6716.1349271308!/suppinfoFile/Kahneman\%20Letter.pdf 
extend theories of social influence and intergroup cognitive mechanisms in the context of strategic decision-making (Finkelstein, Hambrick, and Cannella 2009; Helfat and Peteraf 2015; Narayanan, Zane, and Kemmerer 2011). Likewise, scholarly efforts in leadership and governance literature is starting to converge individual, social constructs to explain organisational-level perspectives (Westphal and Zajac 2013; Zhu, Shen, and Hillman 2014). We believe an integrative behavioural perspective can provide additional benefits to innovation research and practice. First, it is more likely to yield generative theories that generalise to wider $R \& D$ and innovation management literature. Second, it offers a 'gold' standard for studying agentic socio-cognitive capabilities and their influence on behaviour and performance at various stages and in various types of innovation. Third, our humanistic research design approach transcends challenges and assumptions rooted in conventional (and economic) experiments, rather using game-theoretic model as an element of the design and standard for evaluating emergent behavioural theories. Lastly, we hope, that the interdisciplinary aspect of behavioural experiments will bridge the gap between otherwise dispersed group of behavioural scholars (i.e. scholars in behavioural strategy, behavioural economics, behavioural innovation, psychology and organisational behaviour) and innovation practitioners, fostering a more open and collaborative environment for innovation research and practice. Scholars have observed that despite the call for new forms of organizing for innovation in practice, research in the area has mostly tackled question of how to type (Brunswicker and Vanhaverbeke 2015; Frow, Nenonen, Payne, and Storbacka 2015; Naqshbandi, Tabche, and Choudhary 2018), the questions of why and how remain largely unaddressed. These questions reflect practical managerial challenges of who to include in innovation projects? How to improve productivity and creativity of individuals and groups? Why do some individuals embrace open innovation where others do not? What conditions to put in place to improve (or restrict) cooperation and collaborative efforts? From the emerging humanistic perspective to innovation management (Salzmann and Kock, 2018; Simeone, Secundo, and Schiuma 2017), it becomes an imperative to understand how participation in new open and collaborative environments affects individual's socio-cognitive capabilities and well-being. For the practice of innovation management this means humanistic behavioural research methods provide an opportunity to unveil how individuals on an innovation project are influencing outcomes in the context of the specific innovation problem. More broadly, they could inform the firm's human capital policies and decisions related to innovation processes through systematic investigation of the effects of innovation conditions on individual's social and cognitive capabilities, a cause worthy of attention.

For future research, we identify three streams of investigations to advance the science of managing for innovation, although this list is not exhaustive. First, research at the intersection of humanistic principles and innovation performance seems promising. Much of the academic and practice efforts have been directed to human-centred design in recent times (Galle, 2011; Hassi \& Laakso, 2011), yet we know little about firm's share of turnover from innovation and its level of investment in human-centred design approaches. Some recent evidence suggests that this link may be weak (Montresor \& Vezzani, 2019). In addition to the humanistic approach to innovation, collaboration across organisational functions and boundaries has been re-ignited in the previous fifteen years since Chesbrough (2003) drew attention to open innovation practices. An open approach to innovation involves a wide range of stakeholders during the design, development and implementation phases. Thus, a second promising research avenue is to explore the interaction between open innovation and the thinking styles of various stakeholders involved 
in the process. In this view Hassi \& Laakso (2011) refers to thinking styles in terms of cognitive styles, information processing, reasoning approaches and cognitive framing. Lastly, as this editorial series called for intervention in advancing the science of managing for innovation, it is only appropriate to recommend widespread adoption of multi-level, multi-method analysis at the intersection of behavioural science and (open) innovation. As such, humanistic approaches and its ability to shape meaningful innovation should be a key component for research and practice of innovation management.

Innovatively yours,

Anne-Laure Mention, João José Pinto Ferreira, Marko Torkkeli

The Editors

\section{References}

Bogers, M., Zobel, A.K., Afuah, A., Almirall, E., Brunswicker, S., Dahlander, L., Frederiksen, L., Gawer, A., Gruber, M., Haefliger, S. and Hagedoorn, J., 2017. The open innovation research landscape: Established perspectives and emerging themes across different levels of analysis. Industry and Innovation, 24(1), pp.8-40.

Botha, A.P., 2016. Future thinking in R\&D management. In R\&D Management Conference "From Science to Society: Innovation and Value Creation (pp. 1-13).

Branigan, H.P., Pickering, M.J. and Cleland, A.A., 2000. Syntactic co-ordination in dialogue. Cognition, 75(2), pp.B13-B25.

Brunswicker, S. and Chesbrough, H., 2018. The Adoption of Open Innovation in Large Firms: Practices, Measures, and Risks A survey of large firms examines how firms approach open innovation strategically and manage knowledge flows at the project level. Research-Technology Management, 61(1), pp.35-45.

Brunswicker, S. and Vanhaverbeke, W., 2015. Open innovation in small and medium-sized enterprises (SMEs): External knowledge sourcing strategies and internal organizational facilitators. Journal of Small Business Management, 53(4), pp.1241-1263.

Chesbrough, H.W., 2003. Open innovation: The new imperative for creating and profiting from technology. Harvard Business Press, Boston, MA.

Doob, A.N. and Gross, A.E., 1968. Status of frustrator as an inhibitor of horn-honking responses. The Journal of Social Psychology, 76(2), pp.213-218.

Duckworth, A.L. and Kern, M.L., 2011. A meta-analysis of the convergent validity of self-control measures. Journal of research in personality, 45(3), pp.259-268.

Finkelstein, S., Cannella, S.F.B., Hambrick, D.C. and Cannella, A.A., 2009. Strategic leadership: Theory and research on executives, top management teams, and boards. Oxford University Press, USA. 
Frow, P., Nenonen, S., Payne, A. and Storbacka, K., 2015. Managing co-creation design: A strategic approach to innovation. British Journal of Management, 26(3), pp.463-483.

Galle, P., 2011. Foundational and instrumental design theory. Design Issues, 27(4), pp.8194.

Harding, S. A., 2012. "“How do I apply narrative theory?": socio-narrative theory in translation studies." International Journal of Translation Studies, 24(2): 286-309.

Hassi, L. and Laakso, M., 2011. Design thinking in the management discourse: Defining the elements of the concept. 18th International Product Development Management Conference, Delft.

Healey, P. G., Howes, C. and Purver, M., 2010. "Structural divergence in dialogue." In Proceedings of the Conference on Architectures and Mechanisms for Language Processing, Los Angeles, CA. p. 103.

Healey, P. G., Purver, M. and Howes, C., 2014. "Divergence in dialogue." PloS one, 9(6).

Heil, S. and Bornemann, T., 2018. Creating shareholder value via collaborative innovation: the role of industry and resource alignment in knowledge exploration. RESD Management, 48(4), pp.394-409.

Helfat, C.E. and Peteraf, M.A., 2015. Managerial cognitive capabilities and the microfoundations of dynamic capabilities. Strategic Management Journal, 36(6), pp.831-850.

Johnson, M., 2013. "The body in the mind: The bodily basis of meaning, imagination, and reason." Chicago, USA: University of Chicago Press.

Kuhlen, A. K. and Brennan, S. E., 2013. "Language in dialogue: when confederates might be hazardous to your data." Psychonomic bulletin \& review, 20(1): 54-72.

Montresor, S. and Vezzani, A., 2019. Design centrality, design investments and innovation performance: an empirical analysis of European firms. Industrial and Corporate Change. doi: $10.1093 / \mathrm{icc} / \mathrm{dtz} 046$

Narayanan, V.K., Zane, L.J. and Kemmerer, B., 2011. The cognitive perspective in strategy: An integrative review. Journal of Management, 37(1), pp.305-351.

Naqshbandi, M.M., Tabche, I. and Choudhary, N., 2018. Managing open innovation: The roles of empowering leadership and employee involvement climate. Management Decision, 57(3), pp.703723.

Pashler, H. and Harris, C.R., 2012. Is the replicability crisis overblown? Three arguments examined. Perspectives on Psychological Science, 7(6), pp.531-536.

Pashler, H. and Wagenmakers, E.J., 2012. Editors' introduction to the special section on replicability in psychological science: A crisis of confidence?. Perspectives on Psychological Science, 7(6), pp.528-530.

Ruiter, J.P. and Albert, S., 2017. "An appeal for a methodological fusion of conversation analysis and experimental psychology." Research on Language and Social Interaction, 50(1), pp.90107. 
Salampasis, D. and Mention, A.L., 2017. Open Innovation: Unveiling the Power of the Human Element. World Scientific Publishing: Singapore.

Salzmann, E.C. and Kock, A., 2018, July. Does Design Thinking Relate to Team Climate for Innovation in R\&D Projects? A Multi-Level Approach. In Academy of Management Proceedings (Vol. 2018, No. 1, p. 17949). Briarcliff Manor, NY 10510: Academy of Management.

Simeone, L., Secundo, G. and Schiuma, G., 2017. Knowledge translation mechanisms in open innovation: the role of design in R\&D projects. Journal of Knowledge Management, 21(6), pp.14061429.

Shaughnessy, J. J., Zechmeister, E. B. and Zechmeister, J. S., 2015. "Research Methods in Psychology," New York, USA: McGraw-Hill.

Stokoe, E., 2014. The Conversation Analytic Role-play Method (CARM): A method for training communication skills as an alternative to simulated role-play. Research on Language and Social Interaction, 47(3), pp.255-265.

Wagenmakers, E.J., 2007. A practical solution to the pervasive problems of p values. Psychonomic bulletin \& review, 14(5), pp.779-804.

Westphal, J.D. and Zajac, E.J., 2013. A behavioral theory of corporate governance: Explicating the mechanisms of socially situated and socially constituted agency. The Academy of Management Annals, 7(1), pp.607-661.

Wagenmakers, E.J., Wetzels, R., Borsboom, D. and Van Der Maas, H.L., 2011. Why psychologists must change the way they analyze their data: the case of psi: comment on Bem (2011).

Zhu, D.H., Shen, W. and Hillman, A.J., 2014. Recategorization into the in-group: The appointment of demographically different new directors and their subsequent positions on corporate boards. Administrative Science Quarterly, 59(2), pp.240-270. 